\title{
Effects of high pressure versus conventional thawing on the quality changes and myofibrillar protein denaturation of slow/fast freezing beef rump muscle
}

\author{
$\mathrm{Li} \mathrm{LI}^{1 \star}$ (iD)
}

\begin{abstract}
Beef rump muscle samples were frozen by slow freezing $\left(-20^{\circ} \mathrm{C}\right)$ and fast freezing $\left(-80^{\circ} \mathrm{C}\right)$, and subjected to different thawing treatments: air thawing (AT), water immersion thawing (WIT) and high pressure assisted thawing (HPAT) at 50, 100, 150, $200 \mathrm{MPa}$. Temperature and duration of meat samples were monitored during freezing and thawing. The thawing time of AT, WIT and HPAT indicating that HPAT improved the thawing efficiency. HPAT treatment induced the thawing loss and color change, maintained the texture, moisture migration and thermal stability of myofibrillar protein of SF/FF samples. Meanwhile, FF preserved color and inhibited protein oxidation, and the lower protein oxidation were observed in FF-WIT samples. However, the thermal stability of MP depends only on thawing method regardless of SF/FF. High pressure thawing seems to be a complicated process, for which further studies are needed.
\end{abstract}

Keywords: beef rump; high pressure thawing; fast freezing; protein oxidation; particle diameter; moisture migration.

Practical Application: The comparison of air thawing, water immersion thawing and high pressure thawing on the quality changes and protein oxidation of slow/fast freezing beef rump muscle were explored. Water holding capacity, moisture migration, texture, myofibrillar protein thermal stability and particle diameter of different thawing treatments were investigated. The effects of freezing rate (SF/FF) on the quality changes of thawed beef rump muscle were clarified.

\section{Introduction}

With the development of science and technology and the continuous improvement of people's living standard, consumers increasingly seek food that is safe for consumption, high nutritional value, preserved freshness and sensory (Huang et al., 2017). Frozen storage is a widely used method for meat and meat products preservation. Whereas, irreversible damage to the quality of food caused by freezing, especially slow freezing. Previous studies focused on the freezing of meat (aquatic products), but the investigation on thawing is relatively rare. However, thawing is necessary for frozen food before any additional subsequent food processing or cooking. In addition, the thawing process takes much longer than the freezing process, thus potentially further damaging the food texture. Therefore, an important means to reduce the damage of food quality during thawing process is improving the thawing speed (Okamoto \& Suzuki, 2002). Today, high pressure thawing (HPT) is considered the one which can improve frozen food quality.

As a novel non-thermal processing technology, high pressure has been widely applied to researches of sterilization, extraction, shelling, freezing and thawing. Compared with other fields, the function mechanism of the high pressure thawing field is indecisive, and the application in food is not studied comprehensively (Farkas, 2016). Furthermore, the freezing point of water (or melting point of ice) is depressed from $0{ }^{\circ} \mathrm{C}$ to $-21^{\circ} \mathrm{C}$ at about $210 \mathrm{MPa}$ (Bridgman, 1912). Therefore, the driving force (temperature difference) is enhanced effectively and the thawing time is shortened according to Plank's model. Deuchi \& Hayashi (1992) successfully applied high pressure thawing on ice blocks. The results showed that ice blocks subjected to HPT were completely thawed while those left to stand at atmospheric pressure were only partially thawed. Makita (1992) reported that the HPT process of frozen beef at $120 \mathrm{MPa}$ of took one-third the time compared to a process at atmospheric pressure. However, HPT is more complicated than conventional thawing methods, some intricate courses exists, especially compression heating, pressure-dependent temperature change, phase transition and heat transfer (Knorr et al., 1998). Although high pressure treatment can retain nutritional and sensory properties of meat, it has influences on inactivate microorganisms and certain enzymes (Moerman, 2005). In addition, high pressure thawing reduced the total microbial counts by two log cycles (Eshtiaghi \& Knorr, 1996). Thus, high pressure thawing should enhance food quality partly in comparison to conventional thawing processes. However, Okamoto \& Suzuki (2002) observed that the pork meat drip decrease in thawing loss by HPT, and the water holding capacity of the meat improved. At the same time, some remarkable changes were not favorable caused by HPT above $200 \mathrm{MPa}$, such as the regular structure of myofibrils was gradually lost with the increase of the pressure applied. However, to the best of our knowledge, few studies have investigated the effect of protein denaturation and tissue ultrastructure on drip 
loss and texture by HPT and traditional thawing methods, especially on beef meats.

In our study, we employed three thawing methods, including air thawing, water immersion thawing and high pressure thawing, to investigate the role of different thawing treatments on the quality changes and protein denaturation of slow/fast freezing beef. Therefore, the objective of this work was (1) to investigate how high pressure thawing affects the quality of beef and evaluate the industrial feasibility applying high pressure thawing technology to frozen beef; (2) to evaluate the effects of different freezing and thawing treatments on the changes in quality characteristics such as quality changes, thermal stability of MP, moisture migration, and volatile compounds of beef rump samples.

\section{Materials and methods}

\subsection{Materials}

Two isolated beef rump muscles from the same cow were obtained from a local butcher shop (Harbin, Heilongjiang, China) within $48 \mathrm{~h}$ after slaughter and slipped immediately to the laboratory within $20 \mathrm{~min}$. After removing the visible connective tissue and external fat, beef

rump muscles were cut (perpendicular to the fibre direction) into $40 \mathrm{~mm} \times 40 \mathrm{~mm} \times 40 \mathrm{~mm}$ cubes, each weighs $70 \pm 5 \mathrm{~g}$. Before the freezing process, all samples were packaged in vacuumpacked polyethylene bags and pre-cooled in a refrigerator at $4{ }^{\circ} \mathrm{C}$.

\subsection{Freezing and thawing processes}

Experimental grouping and process in this study are shown in Figure 1. The freezing treatments were classified into the following two groups, one group is slow freezing (SF), the other group is fast freezing (FF). The SF samples were frozen in a refrigerator (HYCD-282, Haier, Chian) at $-20^{\circ} \mathrm{C}$, while the FF samples were frozen in the other refrigerator (DW-86W100J) at $-80^{\circ} \mathrm{C}$. The central temperature of the samples was recorded every $1 \mathrm{~s}$ during the freezing process with a temperature detector (Keithley 2700, USA). The samples were immediately moved to a conventional refrigerator $\left(-18^{\circ} \mathrm{C}\right)$ when the central temperature reached $-18^{\circ} \mathrm{C}$ no matter the SF samples or the FF samples, and stored at $-18{ }^{\circ} \mathrm{C}$ for $7 \mathrm{~d}$ until thawing.

The thawing processes is divided into six different methods at $21 \pm 1{ }^{\circ} \mathrm{C}$, including slow freezing-air thawing (SF-AT), slow freezing-water immersion thawing (SF-WIT), slowing freezinghigh pressure assisted thawing (SF-50 MPa, SF-100 MPa, SF$150 \mathrm{MPa}$, SF-200 MPa); fast freezing-air thawing (FF-AT), fast freezing-water immersion thawing (FF-WIT), fast freezing-high pressure assisted thawing (FF-50 MPa, FF-100 MPa, FF-150 MPa, FF-200 MPa). The high pressure assisted thawing was carried out in an ultra-high voltage facility (HPP 3-5 L-600 MPa, Baotoukefa Co., Inner Mongolia, China). Thawing processes were considered complete when the central temperature reached $2{ }^{\circ} \mathrm{C}$, and the thawed samples were stored in a refrigerator $\left(4^{\circ} \mathrm{C}\right)$ for subsequent analysis.

\subsection{Quality changes}

\section{Thawing loss}

Fresh beef rump samples weighed before freezing $\left(M_{0}\right)$, and the thawed samples weighed $\left(\mathrm{M}_{1}\right)$ after their surface moisture was blotted with filter paper. The thawing loss was calculated as the following Equation 1:

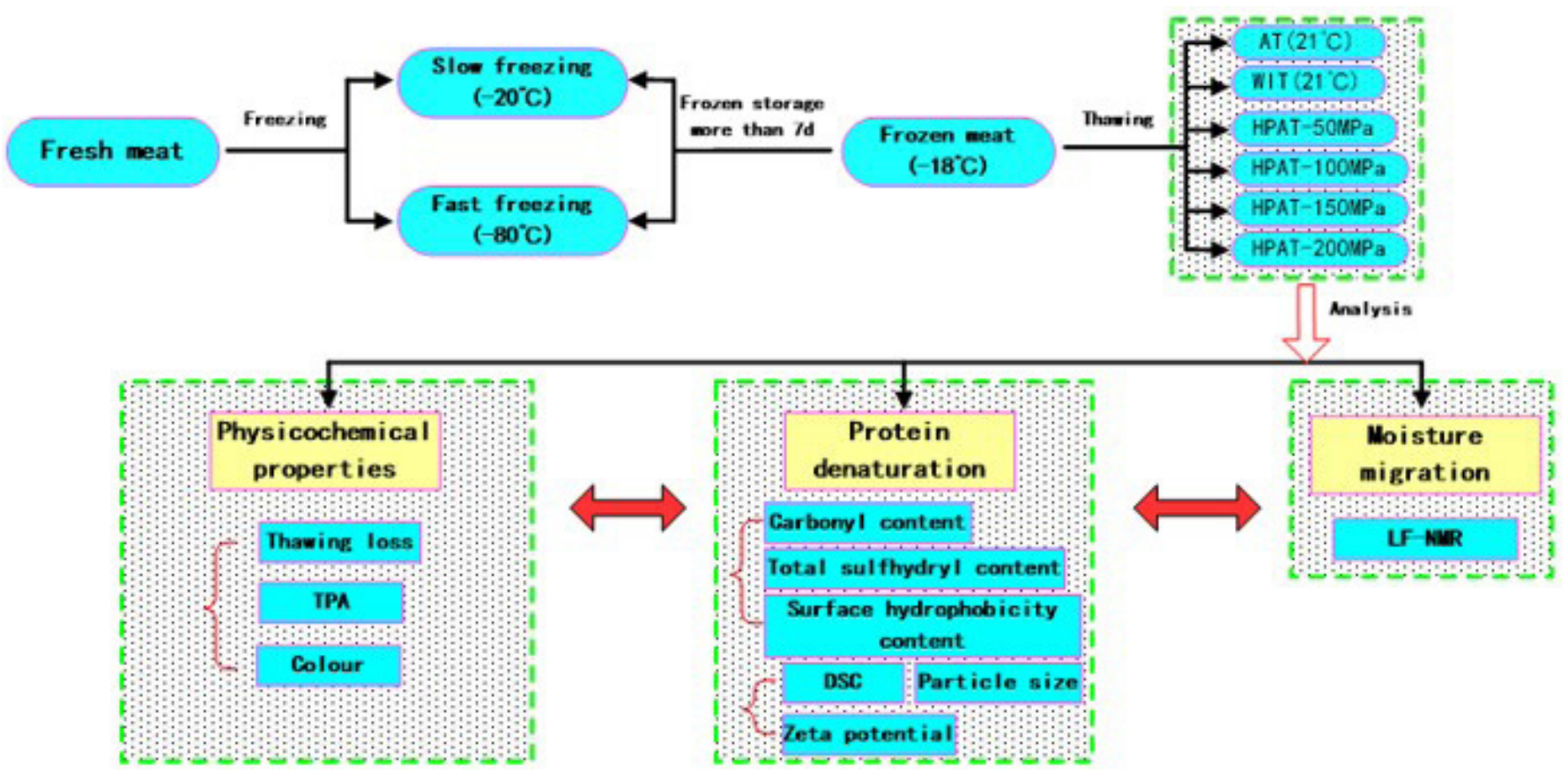

Figure 1. Schematic diagram showing the experimental design. 
Thawing $\operatorname{loss}(\%)=\frac{\mathrm{M}_{0}-\mathrm{M}_{1}}{\mathrm{M}_{0}} \times 100 \%$

Color

The surface color of fresh and treated meat was measured using a colorimeter (NH310, 3nh Co., China). The smaller the value of $\mathrm{L}^{*}$, the smaller the brightness of the sample. The larger the positive value of $a^{*}$, the more red of the sample, the larger the negative value of $\mathrm{a}^{*}$, the more green of the sample. The larger the positive value of $b^{*}$, the more yellow of the sample, the larger the negative value of $b^{*}$, the more blue of the sample. Differences in the color were calculated as using Equation 2:

$\Delta \mathrm{E}=\sqrt{\left(\Delta \mathrm{L}^{*}\right)^{2}+\left(\Delta \mathrm{a}^{*}\right)^{2}+\left(\Delta \mathrm{b}^{*}\right)^{2}}$

Texture profile analysis (TPA)

The TPA of samples were measured using a texture analyzer (Universal TA, Tengba Co., Shanghai, China). All the fresh and frozen-thawed samples were vertically compressed using a cylindrical probe of type $\mathrm{P} / 5$.

\subsection{Protein denaturation}

\section{Carbonyl content}

The carbonyl content of the MP was assayed by reactivity with 2,4-dinitrophenylhydrazine (DNPH) to form protein hydrazones, which following the mean of Peng et al. (2021) with slight modifications. An aliquot of the MP solution $(1 \mathrm{~mL})$ was mixed with $0.01 \mathrm{M} \mathrm{DNPH}(1 \mathrm{~mL})$ and incubated for $1 \mathrm{~h}$ in the dark. Using $1 \mathrm{~mL}$ of $20 \%$ TCA (w/v) and centrifuged to receive the precipitate. The precipitates were washed three times with ethanol: ethyl acetate $(\mathrm{v} / \mathrm{v}=1: 1)$ and then dissolved in $4 \mathrm{~mL}$ of $6 \mathrm{M}$ guanidine. The liquid supernatant was achieved after centrifugation, and the absorbance at $370 \mathrm{~nm}$ was measured. Carbonyl content was expressed as nmol of DNPH fixed per mg of protein using a molar extinction coefficient of 22,000, as the following Equation 3:

$\mathrm{nmol} / \mathrm{mg} \mathrm{MP}=\frac{\mathrm{n} \times 10^{6} \times\left(\mathrm{OD}_{\mathrm{DNPH}}-\mathrm{OD}_{\mathrm{HCl}}\right)}{22000 \times \mathrm{c}}$

Where $\mathrm{n}$ is the dilution ratio, $\mathrm{c}$ is the concentration of MP solution $(\mathrm{mg} / \mathrm{mL})$.

\section{Total sulfhydryl content}

The total sulfhydryl (SH) content was measured by the method of Wang et al. (2020) with minor modifications. MP solution was added into $0.2 \mathrm{M}$ Tris- $\mathrm{HCl}$, then the mixture was centrifuged. The supernatant was mixed with $0.4 \mathrm{M} \mathrm{DTNB}$ for $25 \mathrm{~min}$ at $40{ }^{\circ} \mathrm{C}$. After centrifugation, the absorbance of the supernatant was measured at $412 \mathrm{~nm}$. The total SH content was calculated as nmol per mg protein using a molar extinction coefficient of 136,000, as the following Equation 4:

$\mathrm{nmol} / \mathrm{mg} \mathrm{MP}=\frac{\mathrm{n} \times 10^{6} \times \mathrm{OD}_{412}}{13600 \times \mathrm{c}}$
Where $\mathrm{n}$ is the dilution ratio, $\mathrm{c}$ is the concentration of MP solution $(\mathrm{mg} / \mathrm{mL})$.

\section{Surface hydrophobicity}

Surface hydrophobicity of MP was determined by the content of bound bromophenol blue (BPB) according the way of Chelh et al. (2006) with slight modifications. An aliquot of $1 \mathrm{~mL}$ MP samples were reacted with $1 \mathrm{mg} / \mathrm{mL} \mathrm{BPB}$, the control sample was phosphate buffer instead of MP solution. After agitation at room temperature for $10 \mathrm{~min}$ and centrifugation for $15 \mathrm{~min}$, the supernatant was diluted 10 times with phosphate buffer. The absorbance of the diluted solution was assayed at $595 \mathrm{~nm}$, and the amount of BPB bound was calculated using the following Equation 5:

$\mathrm{BPB}$ bound $(\mu \mathrm{g})=200 \times\left(\mathrm{OD}_{\text {control }}-\mathrm{OD}_{\text {sample }}\right) / \mathrm{OD}_{\text {control }}$

\subsection{Differential scanning calorimetry (DSC)}

Thermal denaturation of muscle proteins was analyzed using a Differential Scanning Calorimeter (204F1, Netzsch Group, Selb, Germany). Chopped samples (5-10 mg) was placed in an aluminum pan keeping a good contact with pan bottom. At least threefold samples were heated from 20 to $90^{\circ} \mathrm{C}$ at a scanning rate of $5 \mathrm{~K} / \mathrm{min}$, with an empty sealed aluminum pan as reference. The denaturation temperature $\left(\mathrm{T}_{\max }\right)$ and total enthalpy $(\triangle \mathrm{H})$ were then estimated from the obtained results.

\subsection{Particle size and Zeta potential}

The particle size of the MP $(1 \mathrm{~mL}, 0.1 \mathrm{mg} / \mathrm{mL})$ was evaluated by a laser analyzer (Nano-ZSE, Malvern Instruments, UK). The mean particle diameters ( $\mathrm{nm}$ ) were obtained using the Zetasizer software provided with the instrument. Each sample was a mean of three readings. Zeta potential of the MP was measured using a laser analyzer (Nano-ZSE, Malvern Instruments, UK) and operated at $25^{\circ} \mathrm{C}$ with electrical field strength of $23 \mathrm{~V} / \mathrm{cm}$.

\subsection{Low-field nuclear magnetic resonance (LF-NMR)}

LF-NMR relaxation measurements were determined through an LF-NMR analyzer (PQ-001, Suzhou Niumag Analytical Instrument Co., Suzhou, China). The treated samples were cut into $1 \times 1 \times 2 \mathrm{~cm}^{3}$ and inserted into a $25 \mathrm{~mm}$ NMR tube. Each measurement was performed in triplicates. The transverse relaxation time $\left(\mathrm{T}_{2}\right)$ was achieved using the Carr-Purcell-Meiboom-Gill (CPMG) with phase cycling to remove artifacts. The obtained $\mathrm{T}_{2}$ data was expressed by using the MultiExp Inv Analysis software (Niumag Electric Corporation, Shanghai, China).

\subsection{Statistical analysis}

Results were analyzed using one-way analysis of variance (ANOVA) and presented as mean values \pm standard deviation (SD). The HSD Tukey's test was applied when the ANOVA showed a significant effect. All figures were plotted using OriginPro 9.1 (OriginLab Co., Northampton, MA, USA). 


\section{Results and discussion}

\subsection{Quality changes}

\section{Freezing and thawing time}

Two freezing rates were tested, a slow freezing rate $\left(-20^{\circ} \mathrm{C}\right)$ obtained in a ordinary freezer, and a fast freezing rate $\left(-80^{\circ} \mathrm{C}\right)$ obtained in a ultra low temperature freezer. The center temperaturetime curves of meat samples treated by SF and FF were shown in Figure 2A. The initial and final criterion temperatures during freezing were respectively $4{ }^{\circ} \mathrm{C}$ and $-18{ }^{\circ} \mathrm{C}$. From Figure $2 \mathrm{~A}$, product temperatures in $\mathrm{FF}$ decreased rapidly without obvious zone of maximum ice crystal formation compared to SF, the duration was respectively 1250 s and 10100 s, reduced $87.6 \%$. The freezing process includes two stages: crystal nucleation and ice crystal production. Once the crystal nucleation is formed, the ice crystal grows rapidly under the action of crystallization driving force, which leads to a series of biochemical reactions in the tissue and decrease the nutritional value and quality of food (Cartagena et al., 2021).

Figure $2 \mathrm{~B}$ illustrates the thawing time of different thawing treatments (AT, WIT, HPAT-50MPa, HPAT-100MPa, HPAT$150 \mathrm{MPa}$, HPAT-200MPa). It is obviously that HPAT shortened the total thawing time, compared with AT (WIT), a time reduction of $84.00 \%$ (58.93\%), $86.47 \%$ (65.29\%), 88.01\% (69.22\%) and $88.79 \%(71.23 \%)$ was noted at power of $50,100,150$ and $200 \mathrm{MPa}$, respectively. A. LeBail et al. (2002) found that the change trends in phase transition time for all groups was similar to the change in total thawing time. Several mechanisms were proposed to explain such a phenomenon. Firstly, with the pressure increasing, the melting temperature and the latent heat of water depressed, which lead to the temperature difference between the sample and the medium in pressure chamber increased and a high heat transfer efficiency achieved. Also, pressurization caused a slight increase in medium temperature and the interior temperature of samples (Denys et al., 2000).

\section{Thawing loss}

Thawing loss is an important index for evaluating the quality of frozen-thawed meat (Cai et al., 2020a), low thawing loss indicates better meat quality. The results from Figure $3 \mathrm{~A}$ showed that the weight loss of conventional thawing methods (AT and WIT) was significantly $(\mathrm{p}<0.05)$ higher than HPAT due to the longer thawing time whatever the freezing process. As the pressure level increased, the thawing loss of FF-HAPT first increased then decreased and the trend was the opposite in SF-HAPT, and the thawing loss of FF-50MPa (0.63\%) and SF-100MPa (2.47\%) were the lowest among all treatments. These results were mainly consistent with those reported in previous studies (Okamoto \& Suzuki, 2002), especially it was reported that $50 \mathrm{MPa}$ was the optimal pressure level in HPT (Deuchi \& Hayashi, 1992), overall the increasing pressure level has a negative effect on thawing loss. The reason may be due to the growth of microorganisms and oxidation of proteins and fats promote damage to the muscle structure and that affects the water reabsorption during the long thawing process (Sun et al., 2021), and the high pressure level led to tissue damage, muscle contraction and myofibrillar proteins aggregation (Jia et al., 2020). As shown in Figure 3A, the freezing process was generally as important as thawing process for thawing loss except for WIT which has no significant differences between SF and FF. It is obviously that the thawing loss of FF was significantly lower than $\mathrm{SF}(\mathrm{p}<0.05)$, which ranged from $0.63 \%$ to $1.37 \%$ for FF and from $2.47 \%$ to $3.32 \%$ for SF, respectively. Due to the lower heat transfer efficiency of SF process and the smaller undercooling, leading to the extracellular solution first crystallized, cell shrinkaged and water loss, and some of the intercellular ice crystals would tear some of the original close connections between cells. In addition, the ice crystals formed are small but large, too large ice crystals
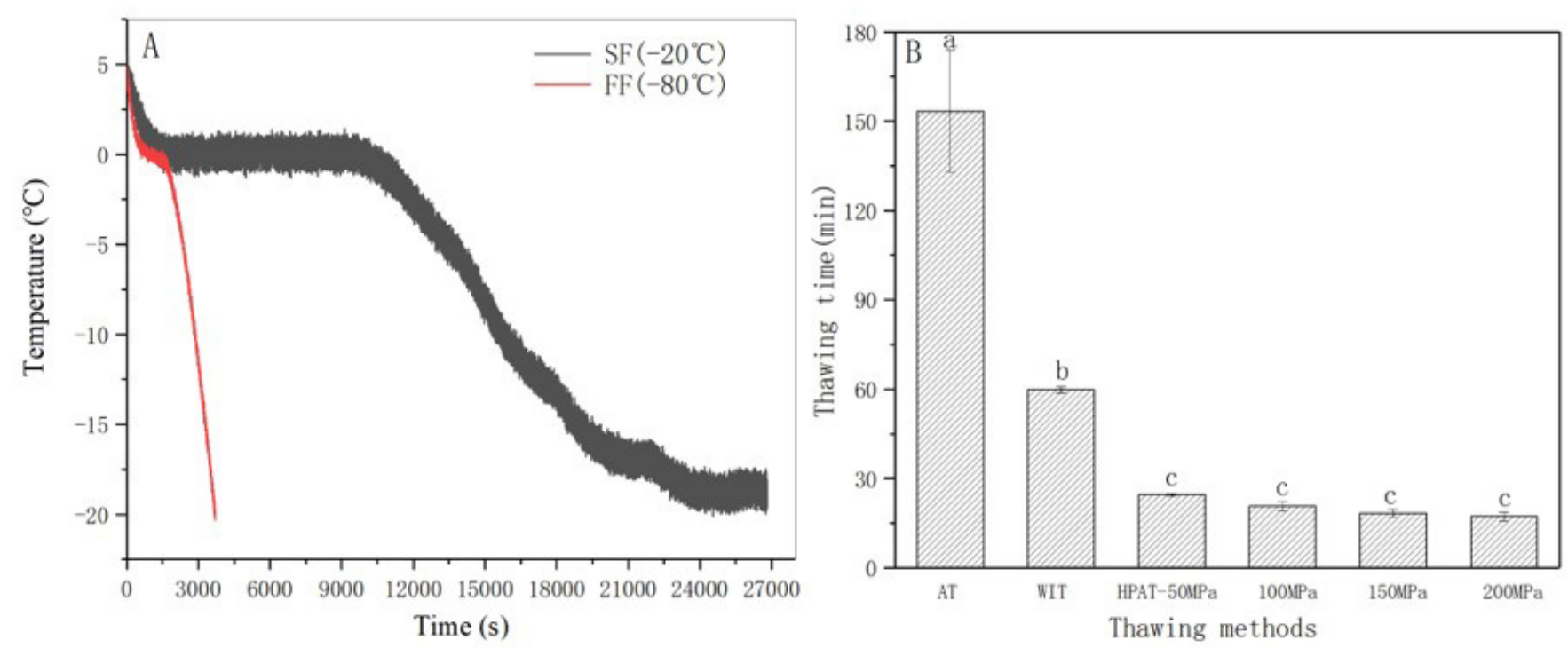

Figure 2. Freezing curves (A), thawing time (B) of beef rump samples. Different letters (a, b, c) in the second column indicate significant difference $(\mathrm{P}<0.05)$ between the thawing treatments. 

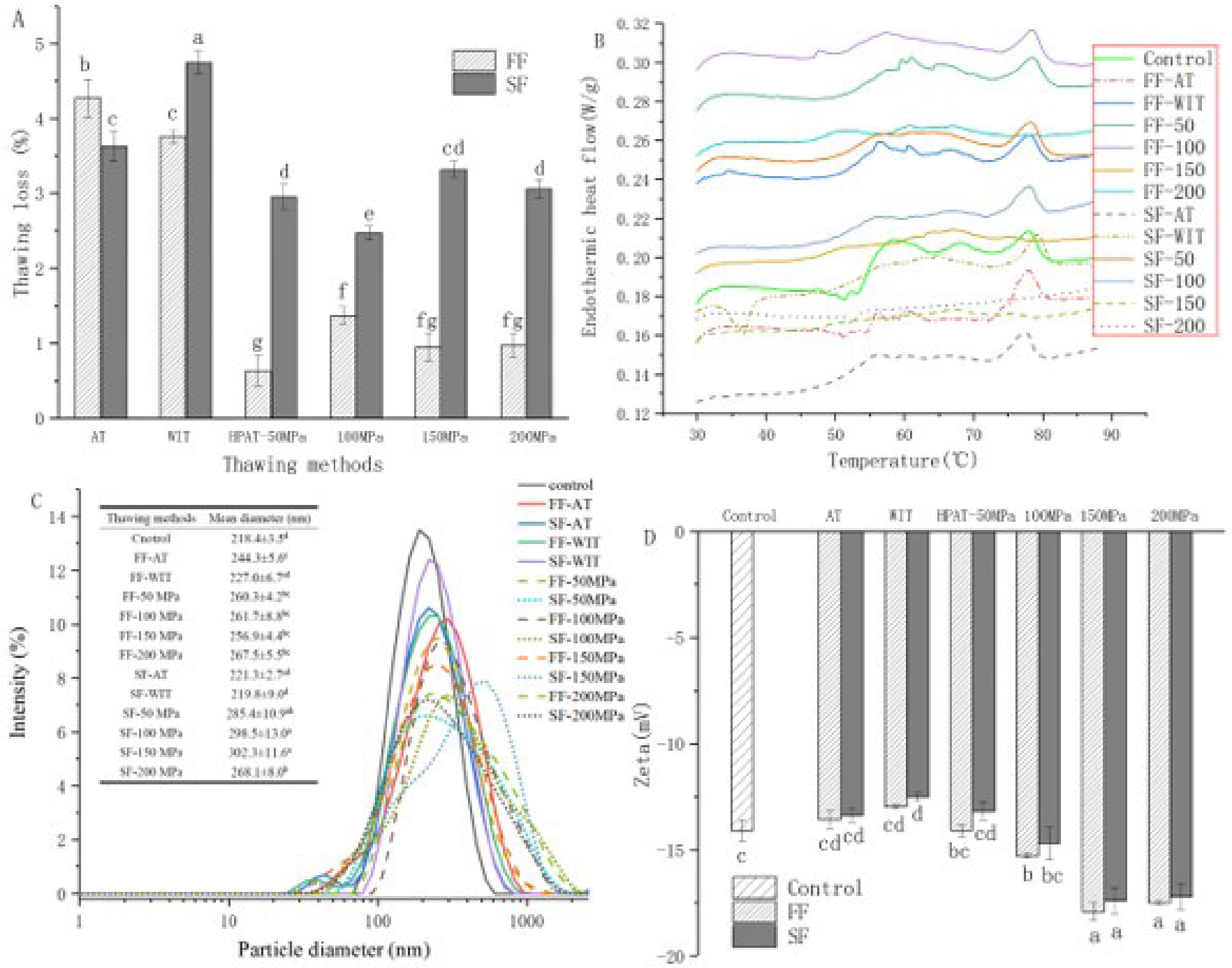

Figure 3. Differences in the thawing loss (A), different scanning calorimetry (DSC) measurement (B), particle diameter (C), Zeta potential (D) of beef rump samples.

can pierce the cell membrane and further damage occurred in the structure.

\section{Color}

Generally, color is an important indicator that affects the meat quality and also influences the consumers' willingness to buy meat (Guo et al., 2021). As showed in Table 1 that all the frozen-thawed samples $L^{*}$ values were significant $(p<0.05)$ higher than fresh meat. The $\mathrm{L}^{*}$ value of $\mathrm{FF}$ was greater than $\mathrm{SF}(\mathrm{p}<0.05)$ as the increasing of pressure level to $150 \mathrm{MPa}$, similar trends in $L^{*}$ value were also observed by $S$. H. Park et al. (2006). The $a^{*}, b^{*}$ values showed a tendency to increase with the pressure increases. Furthermore, the $\triangle \mathrm{E}$ values of $\mathrm{AT}$ and WIT were influenced by the freezing rate resulting in $\mathrm{FF}>\mathrm{SF}$ $(\mathrm{P}<0.05)$. Notwithstanding, the $\triangle \mathrm{E}$ value increased with the increasing of pressure level regardless of freezing rate, and FF was significantly higher than SF $(p<0.05)$ when the pressure level reaches $200 \mathrm{MPa}$. In general, lipid oxidation and pigment degradation during thawing can lead to changes in meat color (Xia et al., 2012). Zare found that high pressure can cause lighter red color in tuna fish meat, which may be caused by the acceleration of astaxanthin and myoglobin oxidation, myofibrillar degeneration (Zare, 2004). Results from the study indicated that the fast freezing rate has a negative impact on reducing the color differences $(\triangle \mathrm{E})$ for conventional thawing treatments (including $\mathrm{AT}, \mathrm{WIT}$ ), and the high freezing rate enhanced the $\triangle \mathrm{E}$ values of HPAT above $150 \mathrm{MPa}$ inversely. Therefore the post processing step must be considered during ongoing investigations to ensure optimal final product quality.

\section{Texture (TPA)}

TPA analysis is an effective and convenient method for rapid detection of influences the sensory and functional characteristics of meat (Cai et al., 2020b). It can be seen from Table 1 that the hardness values of all thawed samples were significantly lower than that of control $(\mathrm{p}<0.05)$ except for FF-50 MPa sample. 


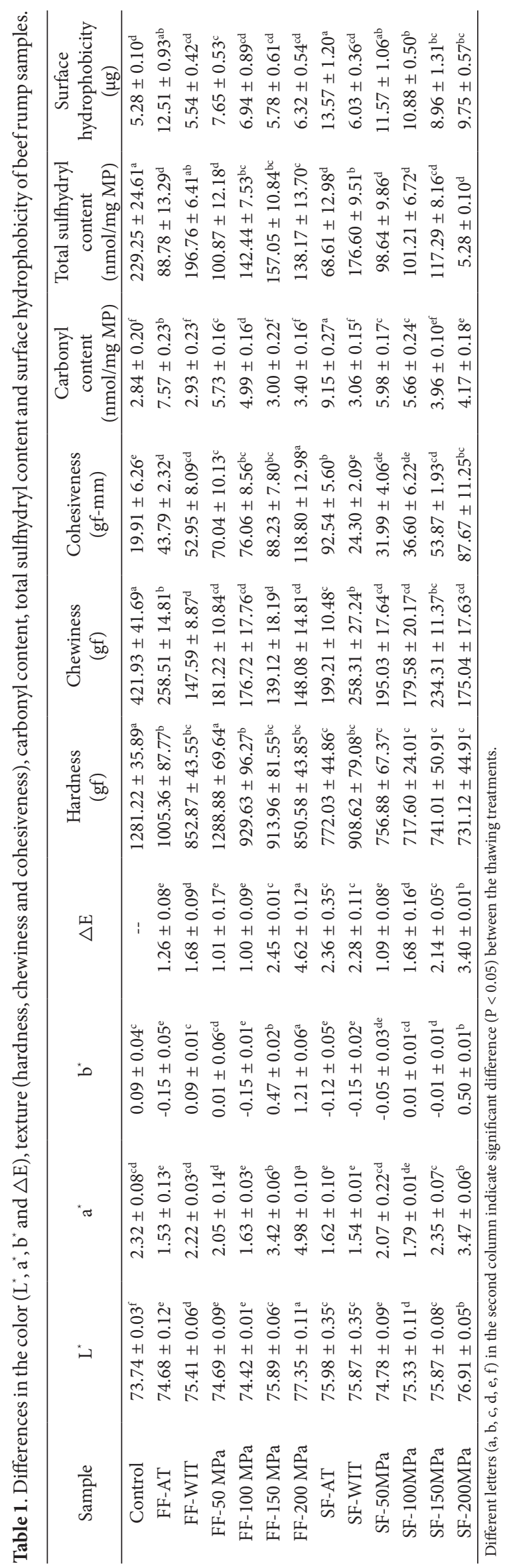


The hardness values of FF samples were higher than SF samples except for FF-WIT < SF-WIT. While it was observed that the conventionally thawed samples appeared flabby, the high pressure thawed ones looked stiff (similar to samples in rigor) (Schubring et al., 2003). In terms of chewiness, all the thawed samples were lower than the control $(\mathrm{p}<0.05)$, and the cohesiveness values of all thawed samples were significantly higher than that of control ( $\mathrm{p}$ $<0.05)$ except for SF-WIT. However, the cohesiveness values of FF were significantly higher than that of SF $(\mathrm{p}<0.05)$ for HPAT. With the increasing pressure, the hardness decreased and the cohesiveness increased. Compared with rapid thawing methods, these differences may have been caused by the thawing time, the longer thawing time the more oxidation of myofibrillar proteins (Jia et al., 2017). Briones-Labarca (2012) indicated that higher values of treated red abalone samples with HP compared with those without pressure for hardness. It was proved that myosin denaturation occurred under high pressure lead to a decreasing in hardness, and the increasing in cohesiveness was attributed to the formation of protein gel under high pressure.

\subsection{Protein denaturation}

\section{Carbonyl, Total sulfhydryl content of MP and Surface hydrophobicity of MP}

Carbonyl, total sulfhydryl content and Surface hydrophobicity of MP may cause changes in functional properties of proteins, which also used to indicate the degree of protein oxidation (Xia et al., 2019). The carbonyl content of all frozen-thawed samples were higher than that of control (Table 1), and SF has significant higher values than $\mathrm{FF}(\mathrm{P}<0.05)$ which employed the thawing methods of AT and HPAT (except HPAT-50 MPa). With the increasing of pressure, carbonyl content decreased first and then increased regardless of SF or FF. The carbonyl content of SF-AT was the largest, and that of FF-WIT was the smallest. These results indicate that the fast freezing and water thawing could partially decrease the degree of protein oxidation, leading to the protein functionalities being maintained. This phenomenon may be due to the release of oxidative enzymes and pro-oxidants from various ruptured cellular organelles (Xia et al., 2009). During the process of freezing and thawing, oxidation of myofibrillar proteins may have a significant impact on texture and function of muscle, while the carbonyl content also result from oxidative peptide scission during the protein oxidation process.

The changes in the total sulfhydryl content of meat samples after frozen-thawed treatments followed a different pattern from protein carbonyl production as showed in Table 1 . The MP oxidation increases with the total sulfhydryl content decreases. All processed samples total sulfhydryl content were lower than control group significantly $(\mathrm{p}<0.05)$, and the total sulfhydryl content of FF samples were higher than SF samples (the value of FF-WIT was largest and that of SF-AT was the lowest). The lowest total SH content of AT might be owing to a longer time in contact with air, which also proved by Jia et al. (2018). In their study, they investigated that the degree of thiol oxidation could be influenced by the thawing rate and oxygen concentration. The loss of the sulfhydryl groups may be due to the formation of disulfide bonds either within polypeptides or between polypeptides and the degradation reactions, which caused the denaturation and aggregation of muscle proteins (Wang et al., 2021).

The increasing in surface hydrophobicity reflects the exposure of hydrophobic residues and protein unfolding. From Table 1, it can be seen that the trend of surface hydrophobicity was mainly the same as that of carbonyl content. Qian et al. (2019) observed that the thawing process causes the exposure of hydrophobic residues. The results demonstrated that FF and WIT could effectively control the increase in surface hydrophobicity of MP, sequentially repressing changes in the protein conformation. In conclusion, the degree of MP oxidation of AT was the most serious and that of WIT was the lightest, while the degree of MP oxidation of HPAT decreased with the increasing pressure.

\section{DSC}

Protein is an important nutrient in meat products, mainly including myofibrin, sarcoplasmic protein and actin. From Figure 3B, three main endothermic regions (Peak 1, 2, 3) were observed, which were assigned to myosin denaturation $\left(57-60^{\circ} \mathrm{C}\right)$, sarcoplasmic protein and collagen denaturation $\left(66-70^{\circ} \mathrm{C}\right)$, and actin denaturation $\left(78-80^{\circ} \mathrm{C}\right)$, respectively (Zhu et al., 2021). The value of $\mathrm{T}_{\max }$ and $\triangle \mathrm{H}$ could reflect whether denaturation happened in protein or not, and there was a negative correlation between the degree of protein denaturation and denaturation enthalpy $(\triangle H)$ (Cao et al., 2018).

From Table 2, $\mathrm{T}_{\max 1}$ of FF-WIT and FF-50 MPa were higher than that of control significantly $(\mathrm{p}<0.05)$. At the same time, $\mathrm{T}_{\max 1}$ decreased significantly $(\mathrm{p}<0.05)$ in high pressure thawing treatment when pressure level above $100 \mathrm{MPa}$, but freezing rate doesn't do much to restrain myosin denaturation. Similarly, FF can not improve the thermal stability of sarcoplasmic protein and collagen, which can be followed the value of $\mathrm{T}_{\max 2}$. Nevertheless, the actin thermal stability decreased significantly $(\mathrm{p}<0.05)$ until the pressure level above $150 \mathrm{MPa}$, and FF decreased more. According to Table 2 and Figure $3 \mathrm{~B}, \triangle \mathrm{H}_{1}$ of all treated samples were lower than that of control significantly $(\mathrm{p}<0.05)$. In term of $\Delta \mathrm{H}_{2}$, the peak area of AT was the smallest, illustrated that damage to the thermal stability of sarcoplasmic protein and collagen denaturation was serious as the lasted long thawing time. Furthermore, with the increasing of pressure, the denaturation enthalpy of FF were larger that of SF significantly $(\mathrm{p}<0.05)$ and the value decreased until pressure reach $200 \mathrm{MPa}$ particularly. At the same time, with an increase in pressure, the peaks of sarcoplasmic protein and actin almost disappeared, which were also verified in Jia et al. (2020). From the results observed in Table 2, FF had a negative effect on the thermal stability of myofibrin protein. It also can be concluded that FF was not promote the thermal stability for HPAT treatments, and this was consistent with the experimental results of Schubring et al. (2003).

\section{Particle size and Zeta potential}

The particle diameter of the MP is a crucial indicator in terms of monitoring the degree of protein aggregation. As shown in the table of Figure 3C, the mean particle diameter and the wideness 
Table 2. Differences in the $T_{\text {max }}$ and $\Delta H$ of beef rump samples.

\begin{tabular}{|c|c|c|c|c|c|c|}
\hline \multirow{2}{*}{ Sample } & \multicolumn{2}{|c|}{ Peak 1} & \multicolumn{2}{|c|}{ Peak 2} & \multicolumn{2}{|c|}{ Peak 3} \\
\hline & $\mathrm{T}_{\max 1}\left({ }^{\circ} \mathrm{C}\right)$ & $\Delta \mathrm{H}_{1}\left(\mathrm{Jg}^{-1}\right)$ & $\mathrm{T}_{\max 2}\left({ }^{\circ} \mathrm{C}\right)$ & $\Delta \mathrm{H}_{2}\left(\mathrm{Jg}^{-1}\right)$ & $\mathrm{T}_{\max 3}\left({ }^{\circ} \mathrm{C}\right)$ & $\Delta \mathrm{H}_{3}\left(\mathrm{Jg}^{-1}\right)$ \\
\hline Control & $58.2 \pm 0.46^{\mathrm{b}}$ & $1.3543 \pm 0.17^{\mathrm{a}}$ & $68.1 \pm 0.70^{\mathrm{a}}$ & $0.2194 \pm 0.04^{\mathrm{cd}}$ & $77.9 \pm 0.45^{\mathrm{a}}$ & $0.5572 \pm 0.04^{\mathrm{a}}$ \\
\hline FF-AT & $57.5 \pm 1.36^{\mathrm{b}}$ & $0.1871 \pm 0.02^{c}$ & $60.9 \pm 0.83^{c}$ & $0.0942 \pm 0.01^{\mathrm{d}}$ & $78.3 \pm 0.46^{\mathrm{a}}$ & $0.5206 \pm 0.04^{\mathrm{a}}$ \\
\hline FF-WIT & $60.6 \pm 1.08^{\mathrm{a}}$ & $0.7240 \pm 0.07^{b}$ & $66.3 \pm 0.61^{\mathrm{ab}}$ & $0.2379 \pm 0.05^{\mathrm{cd}}$ & $78.0 \pm 0.55^{\mathrm{a}}$ & $0.5760 \pm 0.04^{a}$ \\
\hline FF-50 MPa & $61.0 \pm 1.55^{\mathrm{a}}$ & $0.5351 \pm 0.07^{\mathrm{bc}}$ & $65.5 \pm 0.84^{\mathrm{b}}$ & $0.1982 \pm 0.04^{\mathrm{cd}}$ & $78.5 \pm 0.42^{\mathrm{a}}$ & $0.6101 \pm 0.05^{\mathrm{a}}$ \\
\hline FF-100 MPa & $47.6 \pm 0.26^{\mathrm{d}}$ & $0.0488 \pm 0.01^{\mathrm{c}}$ & $57.0 \pm 1.61^{\mathrm{d}}$ & $1.3493 \pm 0.12^{\mathrm{a}}$ & $78.3 \pm 0.68^{\mathrm{a}}$ & $0.5649 \pm 0.05^{\mathrm{a}}$ \\
\hline SF-AT & $57.4 \pm 0.67^{\mathrm{b}}$ & $0.6907 \pm 0.12^{\mathrm{b}}$ & $67.1 \pm 0.25^{\mathrm{ab}}$ & $0.0793 \pm 0.01^{\mathrm{d}}$ & $78.0 \pm 0.46^{\mathrm{a}}$ & $0.5194 \pm 0.08^{\mathrm{a}}$ \\
\hline SF-WIT & $58.1 \pm 0.35^{\mathrm{b}}$ & $0.1785 \pm 0.03^{c}$ & $64.8 \pm 0.55^{\mathrm{b}}$ & $0.3093 \pm 0.03^{c}$ & $79.1 \pm 0.57^{\mathrm{a}}$ & $0.6362 \pm 0.11^{\mathrm{a}}$ \\
\hline SF-50MPa & $56.8 \pm 0.93^{\mathrm{b}}$ & $0.2059 \pm 0.10^{c}$ & $61.5 \pm 0.40^{c}$ & $0.3458 \pm 0.08^{c}$ & $78.3 \pm 0.80^{\mathrm{a}}$ & $0.6261 \pm 0.09^{\mathrm{a}}$ \\
\hline SF-100MPa & $56.1 \pm 0.61^{\mathrm{b}}$ & $0.3217 \pm 0.09^{c}$ & $67.0 \pm 0.61^{\mathrm{ab}}$ & $0.2648 \pm 0.04^{\mathrm{cd}}$ & $77.9 \pm 0.40^{\mathrm{a}}$ & $0.6350 \pm 0.08^{\mathrm{a}}$ \\
\hline SF-150MPa & $50.3 \pm 0.15^{c}$ & $0.3399 \pm 0.15^{c}$ & $66.5 \pm 0.31^{\mathrm{ab}}$ & $0.2807 \pm 0.06^{c}$ & $76.0 \pm 0.36^{\mathrm{b}}$ & $0.0991 \pm 0.01^{\mathrm{b}}$ \\
\hline
\end{tabular}

Different letters $(a, b, c, d)$ in the second column indicate significant difference $(\mathrm{P}<0.05)$ between the thawing treatments.

of particle diameter distribution peak of treated samples were increased compared with that from control group, and freezing methods has no significant difference $(\mathrm{p}>0.05)$ in mean particle diameter of AT and WIT. As shown in Figure 3C, compared to AT and WIT, the mean particle diameter of MP under HPAT increased. Furthermore, it was obvious that slow freezing promoted the growth of mean particle diameter after thawing, and the wideness of particle diameter distribution peak of SF samples were increased which obtained in Figure 3C. It stated that mean particle diameter distribution after SF treatment is more unevenness and instability for HPAT-thawed samples. On the other hand, for HPAT, the mean particles diameter of MP firstly increased and then decreased as the increasing pressure, which also verified by Shi et al. (2019). These results indicated various levels of aggregation appeared in HPAT treated samples. However, Zhang et al. (2021) speculated that a lower $\mathrm{pH}$ and high ionic strength will potentially lead to a transverse shrinkage of the fibers, further more severe protein unfolding as evidenced by increased surface hydrophobicity of myofibrils was caused. In their study, the phenomenon such as the reduced water-holding, increased surface hydrophobicity, increased particle size, and fragmentation of myosin, which evidenced the temporary exposure induced irreversible changes in myofibril structure during thawing. Our results of surface hydrophobicity and mean particle size in this paper were the same as their changes.

Zeta potential is one of the basic parameters that affect the stability of dispersion system and describes the strength of repulsion or attraction between particles (Zhou et al., 2019). As showed in Figure 3D, absolute Zeta potential of AT and WIT were lower than that of control. On the contrary, it is obviously that absolute Zeta potential of HPAT were higher, moreover the value of absolute Zeta potential increased as the increasing pressure. It declared that HP led to strengthen electrostatic repulsions and improve dispersibility and stability of MP particles, which was consistent with the research result of Shi et al. (2019). Nazari et al. (2018) explained that this behavior might be due to the partial unfolding of the protein side chains was beneficial to increase the repulsion between protein molecules, thus avoiding the formation of protein aggregates. Absolute Zeta potential of MP under HPAT significantly increased although the mean particle diameter increased, which indicated that HP treatment can effectively prevent protein oxidation and aggregation and obtain a relatively stable protein solution system.

\subsection{LF-NMR}

LF-NMR is an effective method to measure moisture migration of meat. As shown in Figure 4A and Figure 4B, there were four kinds of water distribution existed in beef rump meat samples, $\mathrm{T}_{2 \mathrm{~b}}(0 \sim 1 \mathrm{~ms}), \mathrm{T}_{21}(1 \sim 10 \mathrm{~ms}), \mathrm{T}_{22}(10 \sim 100 \mathrm{~ms})$, $\mathrm{T}_{23}(100 \sim 1000 \mathrm{~ms})$. The $\mathrm{T}_{2 \mathrm{~b}}$ and $\mathrm{T}_{21}$ both represented bound water which was tightly associated with macromolecules, while $\mathrm{T}_{22}$ and $\mathrm{T}_{23}$ corresponded to the water inside (immobilized water) and outside (free water) the highly organized protein structures, respectively (Sun et al., 2019). It can be seen from the $\mathrm{T}_{2}$ relaxation time in Figure 4, compared to SF, the rapidly forming ice crystals during FF squeezed the myofibrils and promoted the structure tighter, furthermore more stable water molecules were obtained. The $\mathrm{T}_{22}, \mathrm{~T}_{23}$ relaxation time of AT samples were greater than that of other samples, which may be explained by a longer thawing time, thus, providing greater chance for water loss (Sun et al., 2021). Moreover, the shorter thawing time achieved from HPAT reduced the degradation of muscle fibres by microorganisms and enzymes during thawing, thereby improving water retention in thawed meat (Cai et al., 2019). In addition to this, the content of immobilized water $\left(\mathrm{P}_{22}\right)$ decreased significantly $(\mathrm{p}<0.05)$, at the same time the content of free water $\left(\mathrm{P}_{23}\right)$ increased. According to Ruan \& Litchfield (1992), it could be explained that a portion of immobilized water in beef may shift to free water, which may be induced by the water transferring among muscle fibres and the changes in hydrogen bonds between protein and water. However, the thawing loss outflow in the form of free water, the bound water content did not change, the total water volume decreased, the proportion of bound water increased significantly. It also reported that water molecules enter protein molecular holes under pressure 

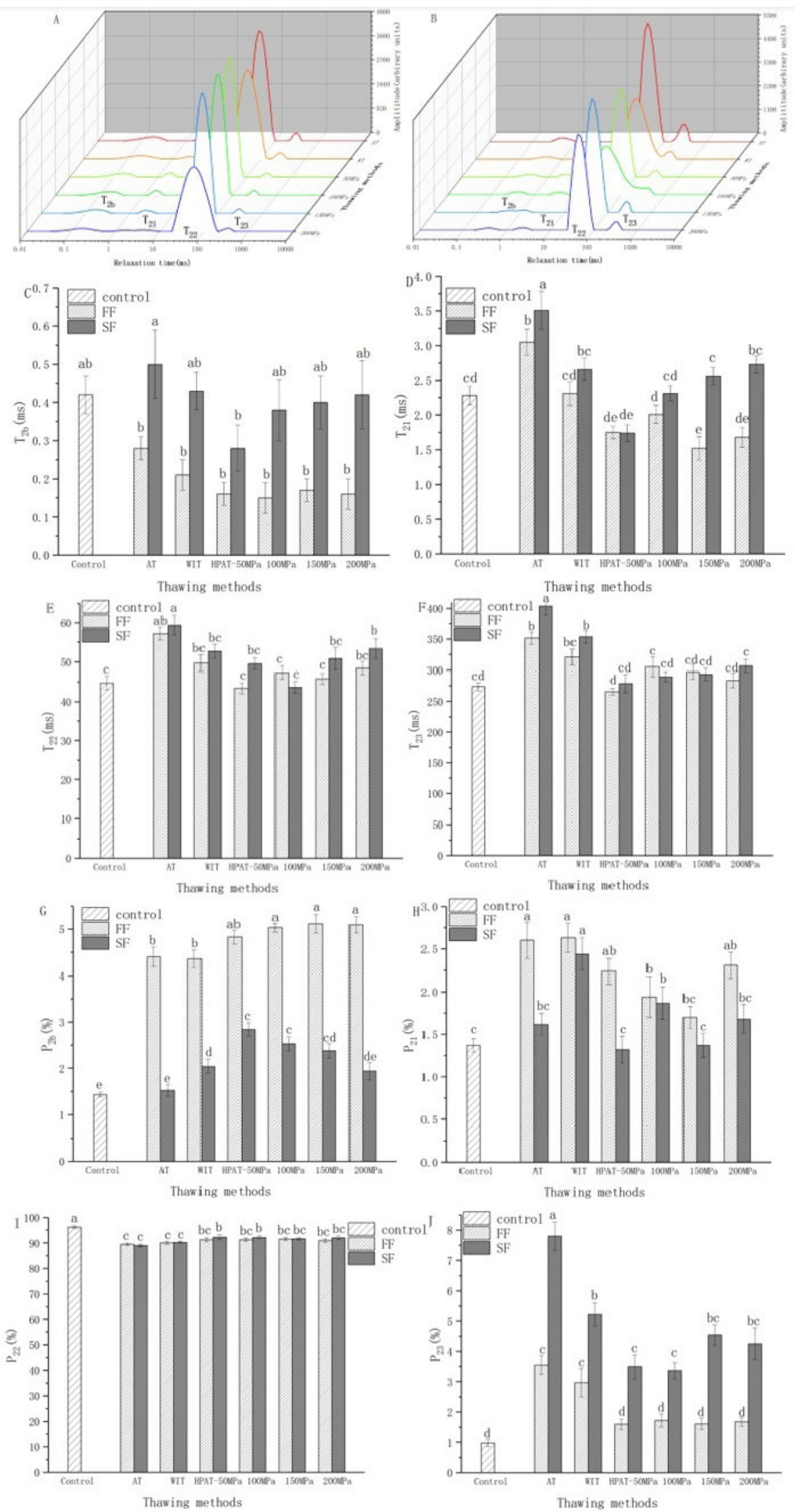

Figure 4. Differences in moisture migration (FF: A, SF: B), T2 relaxation times (T2b: C, T21: D, T22: E, T23:F) and low-field relaxometry proportions of peak areas (P2b: G, P21:H, P22: I, P23: J) of beef rump samples. 
during compression process, then the tightness of the original spatial conformation is reduced, so that more water can be fixed (Hygreeva \& Pandey, 2016). Nevertheless, the $\mathrm{P}_{2 \mathrm{~b}}$ and $\mathrm{P}_{21}$ of SF samples were lower than that of FF samples significantly $(\mathrm{p}<$ 0.05), which illustrated FF treatment is more conducive to the tight binding between water molecules and proteins and improved the hardness and viscosity of samples, which mutually verified with the above TPA experimental results (Table 1).

\section{Conclusion}

In this study, the effects of freezing treatments (slow/fast) and thawing treatments (AT/WIT/HPAT) on the quality of beef rump muscle were evaluated. The results showed that HPAT could dramatically shorten thawing time compared to the conventional thawing methods (AT and WIT), and the thawing time reached a minimum of $17.2 \mathrm{~min}$ as the pressure raised to $200 \mathrm{MPa}$. In the aspect of water holding capacity, the water loss after thawing of HPAT were significant lower than that of the other two conventional thawing methods regardless of FF or SF, FF-50 MPa was the lowest. In comparison to SF treatment, FF treatment preserved the color and inhibited protein oxidation. Among all the treatments, FF-50 MPa had the lowest $\triangle \mathrm{E}$ and the largest hardness, the protein oxidation of FF-WIT was the lowest. However, FF treatment had no significant effect on the thermal stability of MP. In conclusion, FF-50 MPa was the best treatment for protein thermal stability and texture change during thawing; FF-WIT was the best treatment for MP denaturation and particle size distribution.

\section{Reference}

Bridgman, P. W. (1912). Water in the liquid and five solid forms under pressure. Proceedings of the American Academy of Arts and Sciences, 47(13), 441-558. http://dx.doi.org/10.2307/20022754.

Briones-Labarca, V., Perez-Won, M., Zamarca, M., Aguilera-Radic, J. M., \& Tabilo-Munizaga, G. (2012). Effects of high hydrostatic pressure on microstructure, texture, colour and biochemical changes of red abalone (Haliotis rufecens) during cold storage time. Innovative Food Science \& Emerging Technologies, 13, 42-50. http://dx.doi. org/10.1016/j.ifset.2011.09.002.

Cai, L., Dai, Y., \& Cao, M. (2020b). The effects of magnetic nanoparticles combined with microwave or far infrared thawing on the freshness and safety of red seabream (Pagrus major) fillets. LWT, 128, 109456. http://dx.doi.org/10.1016/j.lwt.2020.109456.

Cai, L., Dai, Y., Cao, A., \& Cao, M. (2020a). The effects of CS@Fe3O4 nanoparticles combined with microwave or far infrared thawing on microbial diversity of red seabream (Pagrus major) fillets based on high-throughput sequencing. Food Microbiology, 91, 103511. http:// dx.doi.org/10.1016/j.fm.2020.103511. PMid:32539943.

Cai, L., Zhang, W., Cao, A., Cao, M., \& Li, J. (2019). Effects of ultrasonics combined with far infrared or microwave thawing on protein denaturation and moisture migration of Sciaenops ocellatus (red drum). Ultrasonics Sonochemistry, 55, 96-104. http://dx.doi. org/10.1016/j.ultsonch.2019.03.017. PMid:31084796.

Cao, M., Cao, A., Wang, J., Cai, L., Regenstein, J., Ruan, Y., \& Li, X. (2018). Effect of magnetic nanoparticles plus microwave or farinfrared thawing on protein conformation changes and moisture migration of red seabream (Pagrus Major) fillets. Food Chemistry,
266, 498-507. http://dx.doi.org/10.1016/j.foodchem.2018.06.057. PMid:30381218.

Cartagena, L., Puértolas, E., \& Martínez de Marañón, I. (2021). Impact of different air blast freezing conditions on the physicochemical quality of albacore (Thunnus alalunga) pretreated by high pressure processing. LWT, 145, 111538. http://dx.doi.org/10.1016/j.lwt.2021.111538.

Chelh, I., Gatellier, P., \& Santé-Lhoutellier, V. (2006). A simplified procedure for myofibril hydrophobicity determination. Meat Science, 74(4), 681-683. http://dx.doi.org/10.1016/j.meatsci.2006.05.019. PMid:22063223.

Denys, S., Van Loey, A. M., \& Hendrickx, M. E. (2000). Modeling conductive heat transfer during high-pressure thawing processes: determination of latent heat as a function of pressure. Biotechnology Progress, 16(3), 447-455. http://dx.doi.org/10.1021/bp000018d. PMid:10835248.

Deuchi, T., \& Hayashi, R. (1992). High pressure treatments at subzero temperature: application to preservation, rapid freezing and rapid thawing of foods. INSERM Colloque, 224, 353-355.

Eshtiaghi, M. N., \& Knorr, D. (1996). High hydrostatic pressure thawing for the processing of fruit preparations from frozen strawberries. Food Technology, 10(2), 143-148. http://dx.doi. org/10.1080/08905439609549907.

Farkas, D. F. (2016). A short history of research and development efforts leading to the commercialization of high-pressure processing of food. In V. M. Balasubramaniam, G. V. Barbosa-Cánovas \& H. L. M. Lelieveld (Eds.), High pressure processing of food: principles, technology and applications (pp. 19-36). New York: Springer. http:// dx.doi.org/10.1007/978-1-4939-3234-4_2.

Guo, Z., Ge, X., Yang, L., Ma, G., Ma, J., Yu, Q., \& Han, L. (2021). Ultrasound-assisted thawing of frozen white yak meat: effects on thawing rate, meat quality, nutrients, and microstructure. Ultrasonics Sonochemistry, 70, 105345. http://dx.doi.org/10.1016/j. ultsonch.2020.105345. PMid:32932225.

Huang, H. W., Wu, S. J., Lu, J. K., Shyu, Y. T., \& Wang, C. Y. (2017). Current status and future trends of high-pressure processing in food industry. Food Control, 72, 1-8. http://dx.doi.org/10.1016/j. foodcont.2016.07.019.

Hygreeva, D., \& Pandey, M. C. (2016). Novel approaches in improving the quality and safety aspects of processed meat products through high pressure processing technology - a review. Trends in Food Science \& Technology, 54, 175-185. http://dx.doi.org/10.1016/j. tifs.2016.06.002.

Jia, F., Jing, Y., Dai, R., Li, X., \& Xu, B. (2020). High-pressure thawing of pork: Water holding capacity, protein denaturation and ultrastructure. Food Bioscience, 38, 100688. http://dx.doi.org/10.1016/j.fbio.2020.100688.

Jia, G., Liu, H., Nirasawa, S., \& Liu, H. (2017). Effects of high-voltage electrostatic field treatment on the thawing rate and post-thawing quality of frozen rabbit meat. Innovative Food Science \& Emerging Technologies, 41, 348-356. http://dx.doi.org/10.1016/j.ifset.2017.04.011.

Jia, G., Nirasawa, S., Ji, X., Luo, Y., \& Liu, H. (2018). Physicochemical changes in myofibrillar proteins extracted from pork tenderloin thawed by a high-voltage electrostatic field. Food Chemistry, 240, 910-916. http://dx.doi.org/10.1016/j.foodchem.2017.07.138. PMid:28946361.

Knorr, D., Schlueter, O., \& Heinz, V. (1998). Impact of high hydrostatic pressure on phase transitions of foods. Food Technology, 52(9), 42-45.

LeBail, A., Mussa, D., Rouille, J., Ramaswamy, H. S., Chapleau, N., Anton, M., Hayert, M., Boillereaux, U., \& Chevalier, D. (2002). High pressure thawing. application to selected sea-foods. Progress in Biotechnology, 19, 563-570. 
Makita, T. (1992). Application of high pressure and thermophysical properties of water to biotechnology. Fluid Phase Equilibria, 76, 87-95. http://dx.doi.org/10.1016/0378-3812(92)85079-N.

Moerman, F. (2005). High hydrostatic pressure inactivation of vegetative microorganisms, aerobic and anaerobic spores in pork Marengo, a low acidic particulate food product. Meat Science, 69(2), 225-232. http://dx.doi.org/10.1016/j.meatsci.2004.07.001. PMid:22062812.

Nazari, B., Mohammadifar, M. A., Shojaee-Aliabadi, S., Feizollahi, E., \& Mirmoghtadaie, L. (2018). Effect of ultrasound treatments on functional properties and structure of millet protein concentrate. Ultrasonics Sonochemistry, 41, 382-388. http://dx.doi.org/10.1016/j. ultsonch.2017.10.002. PMid:29137765.

Okamoto, A., \& Suzuki, A. (2002). Effects of high hydrostatic pressure thawing on pork meat. Progress in Biotechnology, 19, 571-576.

Park, S. H., Ryu, H. S., Hong, G. P., \& Min, S. G. (2006). Physical properties of frozen pork thawed by high pressure assisted thawing process. Food Science \& Technology International, 12(4), 347-352. http://dx.doi.org/10.1177/1082013206068037.

Peng, Z., Zhu, M., Zhang, J., Zhao, S., He, H., Kang, Z., Ma, H., \& Xu, B. (2021). Physicochemical and structural changes in myofibrillar proteins from porcine longissimus dorsi subjected to microwave combined with air convection thawing treatment. Food Chemistry, 343, 128412. http://dx.doi.org/10.1016/j.foodchem.2020.128412. PMid:33268166.

Qian, S., Li, X., Wang, H., Mehmood, W., Zhong, M., Zhang, C., \& Blecker, C. (2019). Effects of low voltage electrostatic field thawing on the changes in physicochemical properties of myofibrillar proteins of bovine Longissimus dorsi muscle. Journal of Food Engineering, 261, 140-149. http://dx.doi.org/10.1016/j.jfoodeng.2019.06.013.

Ruan, R. S., \& Litchfield, B. (1992). Determination of water distribution and mobility inside maize kernels during steeping using magnetic resonance imaging. Cereal Chemistry, 69, 13-17.

Schubring, R., Meyer, C., Schluter, O., Boguslawski, S., \& Knorr, D. (2003). Impact of high pressure assisted thawing on the quality of fillets from various fish species. Innovative Food Science \& Emerging Technologies, 2003(4), 257-267. http://dx.doi.org/10.1016/S14668564(03)00036-5.

Shi, X., Zou, H., Sun, S., Lu, Z., Zhang, T., Gao, J., \& Yu, C. (2019). Application of high-pressure homogenization for improving the physicochemical, functional and rheological properties of myofibrillar protein. International Journal of Biological Macromolecules, 138, 425432. http://dx.doi.org/10.1016/j.ijbiomac.2019.07.110. PMid:31326511.

Sun, Q., Kong, B., Liu, S., Zheng, O., \& Zhang, C. (2021). Ultrasoundassisted thawing accelerates the thawing of common carp (Cyprinus carpio) and improves its muscle quality. $L W T, 141,111080$. http:// dx.doi.org/10.1016/j.lwt.2021.111080.
Sun, Q., Sun, F., Xia, X., Xu, H., \& Kong, B. (2019). The comparison of ultrasound-assisted immersion freezing, air freezing and immersion freezing on the muscle quality and physicochemical properties of common carp (cyprinus carpio) during freezing storage. Ultrasonics Sonochemistry, 51, 281-291. http://dx.doi.org/10.1016/j. ultsonch.2018.10.006. PMid:30337027.

Wang, B., Kong, B., Li, F., Liu, Q., Zhang, H., \& Xia, X. (2020). Changes in the thermal stability and structure of protein from porcine longissimus dorsi induced by different thawing methods. Food Chemistry, 316, 126375. http://dx.doi.org/10.1016/j.foodchem.2020.126375. PMid:32062575.

Wang, Z., Tu, J., Zhou, H., Lu, A., \& Xu, B. (2021). A comprehensive insight into the effects of microbial spoilage, myoglobin autoxidation, lipid oxidation, and protein oxidation on the discoloration of rabbit meat during retail display. Meat Science, 172, 108359. http://dx.doi. org/10.1016/j.meatsci.2020.108359. PMid:33160212.

Xia, M., Chen, Y., Guo, J., Feng, X., Yin, X., Wang, L., Wu, W., Li, Z., Sun, W., \& Ma, J. (2019). Effects of oxidative modification on textural properties and gel structure of pork myofibrillar proteins. Food Research International, 121, 678-683. http://dx.doi.org/10.1016/j. foodres.2018.12.037. PMid:31108795.

Xia, X., Kong, B., Liu, J., Diao, X., \& Liu, Q. (2012). Influence of different thawing methods on physicochemical changes and protein oxidation of porcine longissimus muscle. Lebensmittel-Wissenschaft + Technologie, 46(1), 280-286. http://dx.doi.org/10.1016/j.lwt.2011.09.018.

Xia, X., Kong, B., Liu, Q., \& Liu, J. (2009). Physicochemical change and protein oxidation in porcine longissimus dorsi as influenced by different freeze-thaw cycles. Meat Science, 83(2), 239-245. http:// dx.doi.org/10.1016/j.meatsci.2009.05.003. PMid:20416749.

Zare, Z. (2004). High pressure processing of fresh tuna fish and its effects on shelf life. Quebec: Mc Gill University, 45-76.

Zhang, Y., Puolanne, E., \& Ertbjerg, P. (2021). Mimicking myofibrillar protein denaturation in frozen-thawed meat: Effect of $\mathrm{pH}$ at high ionic strength. Food Chemistry, 338, 128017. http://dx.doi.org/10.1016/j. foodchem.2020.128017. PMid:32927203.

Zhou, L., Feng, X., Yang, Y., Chen, Y., Tang, X., Wei, S., \& Li, S. (2019). Effects of high-speed shear homogenization on the emulsifying and structural properties of myofibrillar protein under low-fat conditions. Journal of the Science of Food and Agriculture, 99(14), 6500-6508. http://dx.doi.org/10.1002/jsfa.9929. PMid:31321768.

Zhu, M., Zhang, J., Peng, Z., Kang, Z., Ma, H., Zhao, S., He, H., \& Xu, B. (2021). Fluctuated low temperature combined with high-humidity thawing to retain the physicochemical properties and structure of myofibrillar proteins from porcine longissimus dorsi. LebensmittelWissenschaft + Technologie, 142, 111001. http://dx.doi.org/10.1016/j. lwt.2021.111001. 